\title{
Gaming Addiction and Aggression in Pakistani Young Adults: Through the Lens of Excitation Transfer Theory
}

\author{
Saba Shabir ${ }^{1}$, Dr. Muhammad Saleem ${ }^{2}$, Shazara Mahmood ${ }^{3}$, and Saima Perveen ${ }^{4}$
}

\begin{abstract}
The present study investigated the relationship between gaming addiction and aggression among young adults. 160 participants ( 80 males and 80 females) were approached by purposive sampling. Cross-sectional, correlational research design was employed. The data were collected using two questionnaires: Gaming Addiction Inventory for Adults and The Aggression Questionnaire. The data was analyzed through Statistical Package for the Social Sciences, version 21. Results revealed that gaming addiction has significant but negative relationship with aggression, anger, and physical aggression, however, verbal aggression and hostility were not significantly related. Analysis of gender difference indicated males as more addicted to games than females, while aggression and its variants were not found to be significantly different. The study concluded that video game playing may become a source for releasing aggression, hence, lowering the physiological arousals and reducing aggression in life. The inverse relationship of gaming addiction and aggression implies the positive consideration of games for dealing with aggression among young adults. The study has certain limitations as forthcoming researches should examine the particular types of games with aggression or comparing different age groups will further enlighten the relationship of game playing and aggression.
\end{abstract}

Keywords: Gaming Addiction; Aggression; Young Adults; Excitation Transfer Theory

Received: 16 Jan 2020; Revised Received: 24

June 2020; Accepted: 30 June 2020

${ }^{1}$ Lecturer, Dept. of Applied Psychology, Govt. Sadiq College Women University, Bahawalpur.

${ }^{2}$ Associate Professor, Dept. of Applied Psychology, The Islamia University of Bahawalpur.

${ }^{3}$ Assistant Professor (Psychology), Govt. SE. College, Bahawalpur.

${ }^{4}$ Research Scholar, Dept. of Applied Psychology, The Islamia University of Bahawalpur.

Corresponding Author Email:

sba.shabir@gmail.com

\section{Introduction}

Human life revolves around a number of things and everything should be in a limit to have a balanced life. Over indulgence or total ignorance for certain things may disturb the equilibrium of life. Over indulgence is synonymous with addiction, however, the term "addiction" is ambiguous. Griffiths (1999) classified addiction into two types; chemical and behavioral addiction i.e., extensive substance use or intensively engaged in any behavior, respectively. Furthermore, he sub-classified a new category to the behavioral addiction i.e., technological addiction, which further includes internet or gaming addiction. For some researchers, addiction is a syndrome

This article is distributed under the terms of the Creative Commons Attribution Non Commercial 4.0 License (http://www.creativecommons.org/licenses/by-nc/4.0/) which permits nonCommercial use, reproduction and distribution of the work without further permission provided the original work is attributed as specified. 
(Shaffer et al., 2004), for some, it is intensive involvement in any activity. Shaw and Black (2008) explained the term with reference to extensive internet usage that may lead to distress. However, some researchers (Betz et al., 2000; Grant et al., 2006) have indicated that the behavior related with any type of addiction could be different, but the basic manifestation is quite similar; common neurological responses in the dopamine system. Hence, dopamine system or the brain reward system, when pursued by extensively indulging in any pleasurable activity is addiction that may also lead to psychosocial disturbances (Shaffer et al., 2004). Recently, one of the addictions that has grabbed the attention of researchers for its dysfunctional psychosocial aspects is the gaming addiction.

With the advancement of technology and smartphones, video games have become one of the most popular choice of entertainment and preferred leisure activity. Game playing is a source of enjoyment for many people, but on the other hand, some individuals get extensively indulge into game playing. As spending a lot of time on internet leads to internet addiction (Smahel et al., 2012), similarly, heavy gaming is a strong indicator of gaming addiction. Gaming addiction is defined as impulsive or problematic game playing leading to significant harm (Mentzoni et al., 2011). In addition, Griffiths (2008) elucidated that gaming addiction contains six essential features similar to substance addiction; (a) Salience: games become center of one's life, (b) Mood modification: player experiences pleasure or emotional arousals, (c) Tolerance: players feel compelled to devote more time to video games for seeking pleasure, (d) Withdrawal symptoms: uncomfortable emotions when player stops playing, (e) Relapse: Players quickly returns to the old patterns of playing after some time, (f) Internal conflict or conflict with the surroundings.
A lot of researches have pointed out several explanations for why people get addict to games, for example; social difficulties and stressful life events, as person uses games as emotion centered coping strategy or escapism to deal with stress (Hussain \& Griffiths, 2009), high levels of in-game online social support that may also elevate self-esteem (Longman et al., 2009), hostility is also a risk factor for gaming addiction among children and adolescents (Chiu et al., 2004). In addition, some personality traits such as neuroticism, sensation seeking, trait anxiety, state anxiety, and aggression are associated with excessive game playing (Mehroof \& Griffiths, 2010). Depression and loneliness may also lead to internet addiction, but entertainment is stronger predictor of spending a lot of time online (Kim et al., 2009). Hence, risk factors for gaming addiction ranges from personal to social factors.

Heavy gamers may get addict to any kind of game because video game industry is expanding and players get more variations. According to the content, video games have been characterized into entertainment, educational, and violent games (Ahmed \& Ullah, 2013). However, violent video games have drawn greater attention of researchers, leading them to believe that such kinds of games are associated with hostility and aggression among children and adolescents (Gentile et al., 2011; Staude-Muller, 2011). A study (Griffiths et al., 2004) has found that adolescents and adults are equally attracted to games, but, male adolescents prefer violence in games and sacrifice their education and work for it. Similarly, violent video games are a pivotal risk factor for increased aggressive behavior, aggressive cognition, and aggressive affect and for reduced empathy and pro-social behavior (Anderson et al., 2010). Furthermore, student's vulnerability to hostile behaviors, such as physical fights with others or 
argumentations, and poor school performance is related with excessive playing of video games (Gentile et al., 2004).

Nevertheless, there are studies which focused on gaming addiction and its adverse correlates, irrespective of types of games played. For instance excessive video game playing results into; sleeping problems, depression, suicide ideations, anxiety, obsessions/ compulsions, and alcohol/substance abuse as self-reported by heavy gamers (Wenzel et al., 2009); academic failure among children (Skoric et al., 2009); impaired cognitive task performance as a result of reduced cortical thickness of frontal lobe (Yuan et al., 2013); brain of game addicted individual gets similar to pathological functioning of certain areas (Park et al., 2015); moreover, addicted use of social media among female and video games addiction among male induce symptoms of psychiatric illness such as Attention Deficit Hyperactivity Disorder (ADHD), Obsessive Compulsive Disorder (OCD), anxiety, and depression (Schou et al., 2016). Conversely, Anderson and Murphy (2003) examined the impacts of exposure to violent computer games with respect to gender, and found that even brief exposure to a violent game increases aggressive behavior. They further suggested that the effects of violent games on aggression might be greater when game characters played by game users are of the same gender.

On the contrary, some researchers (Brunborg et al., 2014; Ferguson et al., 2012) have argued that adverse consequences associated with game playing are not the direct outcome of video games, rather they depict the role of some mediating variables, such as other problems in life and antisocial personality traits. Gaming addiction and its consequences are manifested in one's social behavior i.e., extension of harmful effects of gaming addiction from the personal conflicts to the social one in the form of aggression, as supported by several studies from the literature review.

Baron and Bransocmbe (2012) defined the term aggression as any behavior that is intended to harm another person who does not want to be harmed. Aggression is overt and can be observed in the form of shooting, stabbing, hitting, slapping, or cursing someone. It can be expressed directly or indirectly. In addition, aggression could be the outcome of nature, social learning, personality, situational factors, and cultural factors relating to an aggressor.

The positive relationship of gaming addiction with aggression can be explained by Excitation Transfer Theory (Zillmann, 1988). This theory proposes that physiological arousals tend to dissipate slowly over time; therefore, a portion of such arousals may continue to exist as the person moves from one situation to the other. In the light of this theory, it can be suggested that physiological arousals during game playing (more heightened arousals particularly while playing violent games) tend to persist for some time that players might experience in later situations even after they stop playing, as a result, players may act violently. This explanation seems accurate for addicted players and their hostile behaviors. From the same perspective, it can also be suggested that players may have lower level of physiological arousals as violent and aggressive impulses might get dissipate or transfer onto games. This makes person less violent in later situations as lower levels of physiological arousals remains there for a while. From both standpoints, it can be concluded that that physiological arousal (high or low) while playing games tend to persist in later situations and has similar effects.

On the other hand, General Aggression Model (GAM) claims that aggression is initiated by the activation and application of aggression-related knowledge structures 
stored in memory (e.g., scripts or schemas). According to this model, playing a violent game primes aggressive tendencies such as aggressive scripts and perceptual schemata, which in turn increase arousal and create an aggressive affective state. In the case of long term effects, repeated exposure to violent games keeps the aggression related schemata activated, which eventually form an aggressive personality (Anderson et al., 2003; Anderson \& Dill, 2000; Bushman \& Huesmann, 2006). Non-violent content of games has opposite effects.

A study in Pakistan has reported that exposure to violence in video games tends to increase aggression and hostility among children (Fatima \& Ashfaq, 2014). Similarly, pathological video game playing induces aggression and loneliness among adolescents (Qureshi et al., 2013). Besides, gaming addiction and its adverse correlates have been expanded by many researchers all over the world. However, in Pakistan a few researches have looked into the growing issue of gaming addiction among children and adolescents. The present study is intended to explore if gaming addiction and aggression has any relationship among young adults, irrespective of the content of games played. So, the objectives of this research were to investigate the relationship of gaming addiction and aggression among young adults and to find out gender difference for the studied variables. Supporting from the literature, it was hypothesized that gaming addiction and aggression are positively correlated and there is a significant gender difference for gaming addiction and aggression.

\section{Method}

This study employed cross sectional research design and recruited 160 adults (80 males and 80 females) with age range of 19 to 30 years $(M=24.10$ with $S D=2.18)$, working in various institutes of Bahawalpur City. Participants were included in the study on the basis of age and whether or not they played the online video games on smartphones, tablets, and computers. Sample size was calculated using online statistical calculator (www.danielsoper.com). The sample size calculation for one tailed $t$-test with anticipated effect size of 0.8 , statistical power level of 0.85 , and probability level of 0.05 recommends the minimum sample size of 48 (at least 24 per group). However, to avoid attrition, a total of 160 (80 males and 80 females) participants were recruited.

\section{Instruments}

\section{Gaming Addiction Inventory for Adults} The scale developed by Wong and Hodgins (2013) assesses the participant's interference in their social relationships, low life satisfaction, and psychiatric distress as a result of playing video games, suitable for adults with age range 18 and above. It consists of 31 items on 5-points likert scale (ranging from strongly agree to strongly disagree). The scale contains five addictionrelated subscales: loss of control and consequences, agitated withdrawal, coping, mournful withdrawal, and shame; besides, an engagement subscale was also added. The scale shows strong test-retest reliability $(\mathrm{r}=$ 0.92), and its subscales indicated good internal consistency (Chronbach's Alpha ranges from 0.77 to 0.94 ). Reliability analysis for the scale matches with the Chronbach's alpha as reported by the original authors i.e., 0.88 which is satisfactory.

\section{The Aggression Questionnaire}

The Aggression Questionnaire (Buss \& Perry, 1992) consists of 29 items that are divided into four subscales: Physical Aggression, Verbal Aggression, Anger, and Hostility. Items are answered on a 5-point scale ranging from 0 (very uncharacteristic of me) to 5 (very characteristic of me). Psychometric properties are established by Buss and Perry (1992). Reliability 
coefficients for each subscale ranges from 0.82 to 0.90 .

The participants agreed to the terms of informed consent. They were assured of confidentiality of all the data that they had provided and that it would be used for research purpose only. Then, they were requested to fill the questionnaires, placed in the order of Gaming Addiction Inventory for Adults (GAIA) and The Aggression Questionnaire (AQ). The collected data were analyzed by computing correlation, linear regression and independent sample $t$-test using SPSS, version 21.

\section{Results}

\section{Table 1}

Correlations of Studied Variables $(N=160)$

\begin{tabular}{lllllllll}
\hline Variables & $\boldsymbol{M}$ & $\boldsymbol{S D}$ & $\mathbf{1}$ & $\mathbf{2}$ & $\mathbf{3}$ & $\mathbf{4}$ & $\mathbf{5}$ & $\mathbf{6}$ \\
\hline Gaming Addiction & 68.05 & 23.84 & - & & & & & \\
Aggression & 87.96 & 8.88 & $-0.30^{* *}$ & & & & & \\
Physical Aggression & 27.90 & 5.81 & $-0.37^{* *}$ & $0.64^{* *}$ & & & & \\
Verbal Aggression & 15.26 & 3.23 & 0.01 & $0.26^{* *}$ & $-0.19^{*}$ & & & \\
Anger & 21.38 & 4.97 & $-0.19^{*}$ & $0.60^{* *}$ & $0.45^{* *}$ & $-0.25^{* *}$ & & \\
Hostility & 23.41 & 4.82 & 0.08 & $0.26^{* *}$ & $-0.35^{* *}$ & $0.33^{* *}$ & $-0.29^{* *}$ & - \\
\hline
\end{tabular}

Note. Gaming addiction is significantly and negatively correlated with aggression, physical aggression, and anger, though it shows positive but a non-significant relationship with verbal aggression and hostility. Aggression shows positive correlation with its sub-variables, hence showing internal consistency. However, the sub-variables show mixed relationships with one another.

$* * p<0.01$ level (2-tailed)

$* p<0.05$ level (2-tailed)

Table 2

Linear Regression Model with Aggression as Outcome Variable

\begin{tabular}{lllll}
\hline Predictor Variable & $\boldsymbol{B}$ & SE & $\boldsymbol{t}$ & $\boldsymbol{p}$ \\
\hline Constant & 95.68 & & $46.98^{*}$ & .000 \\
Gaming Addiction & -.113 & .028 & $-4.01 *$ & .000 \\
\hline
\end{tabular}

Note. The linear regression model indicates variance of $9.3 \%$ in Aggression due to gaming addiction, $F(1,158)=16.11, p<.001, R^{2}=.093,95 \%$ CI. Gaming Addiction has significant $(p<$ $.05)$ negative correlation with Aggression. $p<0.05$ 
Table 3

Gender Difference for Gaming Addiction and Aggression among Young Adults $(N=160)$

\begin{tabular}{|c|c|c|c|c|c|c|c|}
\hline \multirow[t]{3}{*}{ Variables } & \multicolumn{2}{|l|}{ Male } & \multicolumn{4}{|c|}{ Female } & \multirow[t]{3}{*}{ Cohen's d } \\
\hline & \multicolumn{2}{|c|}{$(n=80)$} & \multicolumn{2}{|c|}{$(n=80)$} & \multirow[t]{2}{*}{$t(\mathbf{1 6 0})$} & \multirow[t]{2}{*}{$p$} & \\
\hline & $M$ & $S D$ & $M$ & $S D$ & & & \\
\hline Gaming Addiction & 80.58 & 19.78 & 55.51 & 20.83 & $7.80 *$ & .000 & 1.23 \\
\hline Aggression & 87.52 & 7.51 & 88.40 & 10.10 & -0.62 & .535 & 0.09 \\
\hline Physical Aggression & 27.56 & 5.46 & 28.25 & 6.15 & -0.74 & .456 & 0.11 \\
\hline Verbal Aggression & 15.38 & 2.90 & 15.13 & 3.54 & 0.48 & .627 & 0.07 \\
\hline Anger & 21.23 & 5.42 & 21.52 & 4.51 & -0.36 & .716 & 0.05 \\
\hline Hostility & 23.33 & 4.55 & 23.48 & 5.12 & -0.19 & .845 & 0.03 \\
\hline
\end{tabular}

Note. Gaming Addiction is significant across gender, Cohen's $d$ also indicate large effect size, while Aggression and its sub-variables are not significant.

$* p<0.01$

\section{Discussion}

Gaming addiction is becoming a social problem as game playing has become more of a habit than a source of entertainment among both males and females, irrespective of age. The current study investigated the relationship of gaming addiction with aggression among young adults and influence of gender on gaming addiction and aggression.

To examine the relationship between gaming addiction and aggression, it was hypothesized that there is a positive relationship between gaming addiction and aggression. Findings revealed that gaming addiction has significant $(p<.01)$ but negative relationship with aggression and physical aggression, moreover, anger is also significantly $(p<.05)$ but negatively correlated with gaming addiction, however, verbal aggression and hostility are not significantly related with gaming addiction. Linear regression was computed to find out variance in aggression due to gaming addiction. Analysis revealed that gaming addiction and aggression has significant negative relationship, $F(1,158)=16.11, p<$ $.001, R^{2}=.093$, and there is total $9.3 \%$ of variance in aggression as accounted for by gaming addiction which implies that only $9.3 \%$ of aggression among young adults has reasons in gaming addiction.

The findings of research indicate the intricate relationship between gaming addiction and aggression; adults may spend a lot of time for gaming and that reduces their level of aggression. This recommends that game playing is used as an indirect way of releasing aggressive tendencies or anger onto game and that in turn reduces aggressive behavior in real life. Other correlational studies about the relationship of video game playing with real-life aggression have reported mixed results. Strong relationship was found by some researches (Anderson \& Dill, 2000; Anderson et al., 2010), however, another research (Colwell \& Kato, 2003) contributed that game playing and its correlates are different in eastern (Japan) and western culture (UK), though aggression and video game playing exhibited positive relationship, but preference for aggressive game playing reduces aggression. This brings insight not only about cultural differences for gaming addiction but also the potential positive effects of game playing. Similarly, Ferguson (2011) expanded the view that antisocial personality traits and depressive symptoms 
predicted youth violence instead of video game playing. These findings were also corresponded by other researches (Brunborg et al., 2014; Ferguson et al., 2012). The inverse relationship of aggression and gaming addiction was elaborated by Wan and Chiou (2006), by documenting that problematic gamers fulfilled their unmet psychological needs through gaming world by considering games as central to their lives to achieve entertainment, emotional coping, escaping from reality and for the satisfaction of autonomy and competency, which means video games help to fulfill unmet needs not only for heavy gamers but for others too.

On the contrary, Coyne et al. (2011) reported that witnessing physical and relational aggression over media perpetuate physical and relational aggression in real life among young adults. The differences of media violence and gaming addiction for fabricating potential effects have been elaborated. While playing a video game, the player acts as a game character, not as an observer, videogame playing is active, covert role-taking, whereas witnessing television or movie violence is a more passive and indirect experience, thus video games influence greatly than television or movie violence (Funk et al., 2004). It helps explain that television and video games have different impacts; witnessing television violence increases aggression, while playing video games releases the aggressive tendencies onto games.

The findings of the present study are also needed to be differentiated from other studies which explored technological addiction and its impacts on Pakistani population. As mentioned in literature review, technological addiction includes internet addiction and gaming addiction; both these types of addictions are different in terms of their consequences. Results of the present study indicated that game playing reduces anger and aggression, whereas internet addiction increases the level of loneliness among undergraduate students (Saleem et al., 2015). Similarly, Facebook addiction has positive relationship with anxiety and depression (Zaffar et al., 2015). This difference can be attributed to the previous explanation for television related aggression such as game playing is more direct and active role-taking activity than witnessing television, or spending time on internet or Facebook, which can further be explained by Excitation Transfer Theory.

The negative correlation of aggression and gaming addiction can be explained by the Excitation Transfer Theory, which states that physiological arousal of player during game playing continues to the later situations. As many researchers (Funk et al., 2004; Wan \& Chiou, 2006) have indicated that playing games help to discharge aggressive impulses onto games, because the player takes an active role for that, thus making player free from such tendencies and lowers their physiological arousals. Consequently, player may feel temperate and relaxed which further continues to the other situations, thus decreasing aggression and anger in real life. This corresponds with the excitation transfer theory, however, the transference is not of excitation but of relaxation.

In Pakistan, many researches have shed light on the growing concern of gaming addiction and its correlates. Some researches (Fatima \& Ashfaq, 2014; Qureshi et al., 2013) have indicated the adverse consequences of game playing in terms of aggression and behavioral problems among children and adolescents. However, there are many other researchers who focused on the bright side of video game playing. Besides, they explored the efficacy of video game playing as a therapeutic intervention. One such study (Sajjad et al., 2014) have enlightened the bright prospects of video game playing in terms of psychotherapy to deal with behavioral problems among children with cancer, for 
game playing proved to be effective in reducing psychological illness related to brain tumor. This may corresponds with the Play-Therapy, the effectiveness of which is well-recognized. The current study supports such positive outcomes of game playing which can be incorporated to deal with numerous behavioral issues in Pakistani context, not only among children and adolescents but adults as well.

Gender differences for gaming addiction and aggression were also examined. Significant gender difference were found for gaming addiction, with male having mean of 80.58 $(S D=19.78)$ and mean for female was 55.51 $(S D=20.83)$. Cohen's $d$ was also computed which shows large effect size. Similar findings have been highlighted by other researchers (Griffiths et al., 2004; Wenzel et al., 2009). This difference can be attributed to gender related norms, culture, and stereotypes (Krahe \& Moller, 2004), which implies that male preference for playing video games is rooted in cultural norms, while female prefer social media websites over video games (Schou et al., 2016).

Additionally, results revealed that aggression and its sub variables are not significantly different between males and females, which infer that male and female are equally aggressive. These results are supported by Graves (2007) in a study indicating that females are equally involved in direct or indirect aggressive behaviors. In addition, Richardson and Hammock (2007) elaborated that gender difference for aggression does not exist into adulthood, though, gender difference for indirect aggression is present among children (Bjorkqvist et al., 1992). Hawley, Card and Little (2007) extended the view about fading gender difference by indicating that both women as well as men are getting aggressive with the underlying perception that being aggressive brings social benefits of high status and appeal. Since, lives of male and female are almost same (centering on family, work, and friends), therefore, less gender difference exists for aggression as well.

\section{Limitations and Recommendations}

The study has certain limitation such as data were confined to only one age group i.e., young adults, and the sub-type of video games played were not examined in the current research. Future researchers should incorporate different age groups for comparison. Sub-types of games and amount of time spent for game playing may enhance the understanding of video games and its potential positive and negative aspects.

\section{Conclusion}

The present study highlighted the relationship of gaming addiction and aggression among young adults. Significant negative correlation was found between the gaming addiction and aggression which provides insight about video game playing and their potential positive aspects, suggesting that video game playing helps in releasing aggressive tendencies. Results about gender difference explains that male are more addicted to games than female, while level of aggression was found to be equal for both genders. This also proves that with the advancements and changing lifestyles, both male and female are equally aggressive. The study carries important implications regarding game playing and controlling aggression among young adults.

\section{Conflict of Interest}

The authors reported no conflict of interest.

\section{Source of Funding}

The authors declare no source of funding.

\section{References}

Ahmed, U., \& Ullah, I. (2013). Video Games Addiction: Positive and Negative Effects of Playing Video Games on 
Youth and Children. University of Boras: Sweden

Anderson, C. A., Berkowitz, L., Donnerstein, E., Huesmann, L.R., Johnson, J.D., Linz, D., . . . Wartella, E. (2003). The Influence of Media Violence on Youth. Psychological Science in the Public Interest, 4(3), 81-110. doi: 10.1111/j.15291006.2003.pspi_1433.x

Anderson, C.A., \& Dill, K.E. (2000). Video games and aggressive thoughts, feelings, and behavior in the laboratory and in life. Journal of Personality and Social Psychology, 78(4), 772-790.

Anderson, C.A., Shibuya, A., Ihori, N., Swing, E.L., Bushman, B.J., Sakamoto, A., ... Saleem, M. (2010). Violent video game effects on aggression, empathy, and prosocial behavior in eastern and western countries: a meta-analytic review. Psychological Bulletin, 136(2), 151173. doi: 10.1037/a0018251

Anderson, C.A., \& Murphy, C.R. (2003). Violent video games and aggressive behavior in young women. Aggressive behavior, 29(5), 423-429.

Baron, R.A., \& Branscombe, R.N. (2012). Aggression: Its nature, causes, and control. In Social Psychology (13th ed.). USA: Pearson Education.

Betz, C., Mihalic, D., Pinto, M.E., \& Raffa, R.B. (2000). Could a common biochemical mechanism underlie addictions? Journal of Clinical Pharmacy and Therapeutics, 25(1), 11-20.

Björkqvist, K., Lagerspetz, K.M., \& Kaukiainen. A. (1992). Do girls manipulate and boys fight? Developmental trends in regard to direct and indirect aggression. Aggressive Behavior, 18, 117-127.
Brunborg, G.S., Mentzoni, R.A., \& Froyland, L.R. (2014). Is video gaming, or video game addiction, associated with depression, academic achievement, heavy episodic drinking, or conduct problems? Journal of Behavioral Addictions, 3(1), 27-32. doi: 10.1556/JBA.3.2014.002

Bushman, B.J., \& Huesmann, L.R. (2006). Short-term and long-term effects of violent media on aggression in children and adults. Archives of Pediatrics \& Adolescent Medicine, 160(4), 348-352. doi: 10.1001/archpedi.160.4.348

Buss, A.H., \& Perry, M. (1992). The aggression questionnaire. Journal of Personality and Social Psychology, 63(3), 452.

Chiu, S.I., Lee, J.Z., \& Huang, D.H. (2004). Video game addiction in children and teenagers in Taiwan. Cyber Psychology and Behavior, 7(5), 571581. doi: 10.1089/cpb.2004.7.571

Colwell, J., \& Kato, M. (2003). Investigation of the relationship between social isolation, self-esteem, aggression and computer game play in Japanese adolescents. Asian Journal of Social Psychology, 6(2), 149-158.

Coyne, S.M., Nelson, D.A., Graham-Kevan, N., Tew, E., Meng, K.N., \& Olsen, J.A. (2011). Media depictions of physical and relational aggression: connections with aggression in young adults' romantic relationships. Aggressive Behavior, 37(1), 56-62. doi: 10.1002/ab.20372

Fatima, H., \& Ashfaq, A. (2014). Induction of Violent Characters through Video Games: A case study of Primary School going Children in Pakistan. The International Asian Research Journal, 2(3), 17-24.

Ferguson, C.J. (2011). Video games and youth violence: a prospective analysis 
in adolescents. Journal of Youth and Adolescence, 40(4), 377-391. doi: 10.1007/s10964-010-9610-x

Ferguson, C.J., San-Miguel, C., Garza, A., \& Jerabeck, J.M. (2012). A longitudinal test of video game violence influences on dating and aggression: a 3-year longitudinal study of adolescents. Journal of Psychiatric Research, 46(2), 141-146. doi: 10.1016/j.jpsychires.2011.10.014

Funk, J.B., Baldacci, H.B., Pasold, T., \& Baumgardner, J. (2004). Violence exposure in real-life, video games, television, movies, and the internet: is there desensitization? Journal of Adolescence, 27(1), 23-39. doi: 10.1016/j.adolescence.2003.10.005

Gentile, D.A., Choo, H., Liau, A., Sim, T., Li, D., Fung, D., \& Khoo, A. (2011). Pathological video game use among youths: a two-year longitudinal study. Pediatrics, 127(2), 319-329. doi: 10.1542/peds.2010-1353

Gentile, D.A., Lynch, P.J., Linder, J.R., \& Walsh, D.A. (2004). The effects of violent video game habits on adolescent hostility, aggressive behaviors, and school performance. Journal of Adolescence, 27(1), 5-22. doi:10.1016/j.adolescence.2003.10.0 02

Grant, J.E., Brewer, J.A., \& Potenza, M.N. (2006). The neurobiology of substance and behavioral addictions. CNS Spectrums, 11(12), 924-930.

Graves, K.N. (2007). Not always sugar and spice: Expanding theoretical and functional explanations for why females aggress. Aggression and Violent Behavior, 12, 131-140.

Griffiths, M.D. (1999). Internet addiction: Fact or fiction? The Psychologist, 12, 246-251. http://www.thepsychologist.org.uk/
Griffiths, M.D. (2008). Diagnosis and management of video game addiction. New Directions in Addiction Treatment and Prevention. 12, 27-41

Griffiths, M.D., Davies, M.N., \& Chappell, D. (2004). Online computer gaming: a comparison of adolescent and adult gamers. Journal of Adolescence, 27(1), 87-96. doi: 10.1016/j.adolescence.2003.10.007

Hawley, P.H., Card, N., \& Little, T.D. (2007). The allure of a mean friend: Relationship quality and processes of aggressive adolescents with prosocial skills. International Journal of Behavioral Development, 32, 21-32.

Hussain, Z., \& Griffiths, M.D. (2009). The attitudes, feelings, and experiences of online gamers: a qualitative analysis. Cyber Psychology and Behavior, 12(6), 747-753. doi: 10.1089/cpb.2009.0059

Kim, J., LaRose, R., \& Peng, W. (2009). Loneliness as the cause and the effect of problematic Internet use: the relationship between Internet use and psychological well-being. Cyber Psychology and Behavior, 12(4), 451-455. doi: 10.1089/cpb.2008.0327

Krahe, B., \& Moller, I. (2004). Playing violent electronic games, hostile attributional style, and aggressionrelated norms in German adolescents. Journal of Adolescence, 27(1), 53-69. doi:

10.1016/j.adolescence.2003.10.006

Longman, H., O'Connor, E., \& Obst, P. (2009). The effect of social support derived from World of Warcraft on negative psychological symptoms. Cyber Psychology and Behavior, 12(5), 563-566. doi: 10.1089/cpb.2009.0001

Mehroof, M., \& Griffiths, M.D. (2010). Online gaming addiction: the role of 
sensation seeking, self-control, neuroticism, aggression, state anxiety, and trait anxiety. Cyber Psychology Behavior and Social Networking, 13(3), 313-316.

Mentzoni, R.A., Brunborg, G.S., Molde, H., Myrseth, H., Skouveroe, K.J., Hetland, J., \& Pallesen, S. (2011). Problematic video game use: estimated prevalence and associations with mental and physical health. Cyber Psychology Behavior and Social Networking, 14(10), 591596. doi: 10.1089/cyber.2010.0260

Park, C.H., Chun, J.W., Cho, H., Jung, Y.C., Choi, J., \& Kim, D.J. (2015). Is the Internet gaming-addicted brain close to be in a pathological state? Addiction Biology. doi:10.1111/adb.12282

Qureshi, H.S., Khan, M.J., \& Masroor, U. (2013). Increased Aggression and Loneliness as Potential Effects of Pathological Video-Gaming among Adolescents. Pakistan Journal of Social and Clinical Psychology, 11 (1), 66-71

Richardson, D.S., \& Hammock, G. (2007). Social context of human aggression: Are we paying too much attention to gender? Aggression and Violent Behavior, 12, 417-426.

Saleem, M., Waseem, M., Khan, R., \& Ismail, R. (2015). Internet Addiction: It's Relation with Loneliness among Undergraduate Students of SouthPunjab, Pakistan. Science International Lahore, 27(2), 14691479.

Sajjad, S., Abdullah, A.H., Sharif, M., \& Mohsin, S. (2014). Psychotherapy through Video Game to Target Illness Related Problematic Behaviors of Children with Brain Tumor. Current Medical Imaging Reviews. 10, 62-72
Schou, A. C., Billieux, J., Griffiths, M.D., Kuss, D.J., Demetrovics, Z., Mazzoni, E., \& Pallesen, S. (2016). The relationship between addictive use of social media and video games and symptoms of psychiatric disorders: A large-scale crosssectional study. Psychology of Addictive Behaviors, 30(2), 252-262. doi: 10.1037/adb0000160

Shaffer, H.J., LaPlante, D.A., LaBrie, R.A., Kidman, R.C., Donato, A.N., \& Stanton, M.V. (2004). Toward a syndrome model of addiction: multiple expressions, common etiology. Harvard Review of Psychiatry, 12(6), 367-374. doi: 10.1080/10673220490905705

Shaw, M., \& Black, D.W. (2008). Internet addiction: definition, assessment, epidemiology and clinical management. CNS Drugs, 22(5), 353365.

Skoric, M.M., Teo, L.L., \& Neo, R.L. (2009). Children and video games: addiction, engagement, and scholastic achievement. Cyber Psychology and Behavior, 12(5), 567-572. doi: 10.1089/cpb.2009.0079

Smahel, D., Brown, B.B., \& Blinka, L. (2012). Associations between online friendship and Internet addiction among adolescents and emerging adults. Developmental Psychology, 48(2), 381-388. doi: $10.1037 / \mathrm{a} 0027025$

Staude-Muller, F. (2011). Violent video games and aggression: long-term impact and selection effects. Praxis der Kinderpsychologie und Kinderpsychiatrie, 60(9), 745-761. doi: 10.13109/prkk.2011.60.9.745

Wan, C.S., \& Chiou, W.B. (2006). Psychological motives and online games addiction: a test of flow theory and humanistic needs theory for 
Taiwanese adolescents. Cyber Psychology and Behavior, 9(3), 317324. doi: 10.1089/cpb.2006.9.317

Wenzel, H.G., Bakken, I.J., Johansson, A., Gotestam, K.G., \& Oren, A. (2009). Excessive computer game playing among Norwegian adults: selfreported consequences of playing and association with mental health problems. Psychological Reports, 105(3 Pt 2), 1237-1247. doi: 10.2466/PR0.105.F.1237-1247

Wong, U., \& Hodgins, D.C. (2013). Development of the game addiction inventory for adults (GAIA). Addiction Research and Theory, 22(3), 1-15. doi:10.3109/16066359.2013.824565

Yuan, K., Cheng, P., Dong, T., Bi, Y., Xing, L., Yu, D., . . . Tian, J. (2013). Cortical thickness abnormalities in late adolescence with online gaming addiction. PLoS One, 8(1), 53055. doi:10.1371/journal.pone.0053055

Zaffar, M., Mahmood, S., Saleem, M., \& Zakaria, E. (2015). Facebook Addiction: Relation with Depression, Anxiety, Loneliness and Academic Performance of Pakistani Students. Science International Lahore, 27(3), 2469-2475.

Zillmann, D. (1988). Cognition-excitation interdependencies in aggressive behavior. Aggressive Behavior, 14, 51-64. 